\title{
Outside the Family of Nations: First Thoughts on Writing a History of Public Health from the Perspective of Outlier Nations
}

Susan Gross Solomon, Lion Murard

\section{Summary}

Notwithstanding the current declarations by spokesmen for and proponents of global health, there remain "outlier" countries: countries unwilling to accede to monitoring or surveillance (e.g. China and avian flu; China and SARS); countries lacking the infrastructural and professional capacity to join cooperative global programs to fight epidemics; countries/regions that have populations with divergent approaches to health goals and practices.

What, if any, are the historical precedents of the idea of "outliers"? The paper will argue that in the three decades between 1920 and 1950, internationally-minded statesmen, working in philanthropies with transnational "reach" or in international health agencies, operated with two additional categories of outliers.

First, countries with political systems judged "inimical" to democracy (e.g. Soviet Russia, post-war Germany). International public health statesmen often engaged such countries by hiving off (at least notionally) the political system from public health. What was the cost to the understanding of public health of the hiving off of the political? At other times, international health spokesmen explicitly linked transnational cooperation/assistance they offered to a program of democratization. To what extent was that linkage accepted by leading health voices in the target countries?

Second, there were countries whose health "civilizations" had not yet progressed fully beyond nineteenth century public hygiene. Including these countries in international health programs involved nothing less than pushing out the frontiers of civilization. In dealing with these countries, health

Susan Gross Solomon, Munk School of Global Affairs, University of Toronto (susan.solomon@ utoronto.ca); Lion Murard, CNRS/INSERM (lion.murard@cnrs.fr) 
statesmen operated with the initial assumption that capacity and orientation to social medicine could be shaped from the outside. Extended experience on the ground (site visits, field work, cooperative programs) convinced those statesmen of the value of local (and regional) approaches and of the possibility of combining those approaches with international ways of conceptualizing public health. What factors shaped the inclusion/exclusion of countries from the category of "civilized" nations?

Keywords: International health, transnational cooperation, "outlier" countries, Soviet Russia, Greece, social medicine

Histories of international public health in its formative period between the world wars have tended to celebrate achievements - whether the enrolling of a wide range of nations in programs to improve health and prevent disease, the adoption of shared standards and measurements to track health status, or the circulation of health researchers and statesmen across national frontiers. However justified the trumpets, their repeated sounding may have crowded out the existence of system "outliers" in the international health arena. To be sure, in Paul Weindling's 1995 pioneering collection on the "brave new world of international health" and in John Krige's 2012 edited volume on American foundations and the "co-production" of world order, there are references to outliers, ${ }^{1}$ but historians await a sustained analysis of the significance of those outliers for the self-definition of the emerging system.

This paper will focus on outliers as "the other side of the coin" of the design and practice of an inclusive international health arena. At the core of the paper are two questions: first, what can the treatment of certain countries as "outliers" tell us about the international health system that was being constructed in the inter-war years - its normative outlines, processes of evaluation, and collective identity? Some might see the existence of outliers as an indicator of a failed system; historian of international organizations Ayse Zarakol insists that exclusion is not a symptom of the breakdown of international society, but rather a token of its increasing social integration. ${ }^{2}$ Second, what do the strategies deployed by "outliers" to cope with exclusion suggest about the international system? In her canvass of the strategies adopted by "transgressive" states to manage the shame associated with exclusion, sociologically-oriented political scientist Rebecca Adler-Nissen identified the recognition of stigma, the rejection of stigma, and the deployment of counter-stigma. ${ }^{3}$ While these coping strategies testify to agency of

1 Weindling 1995; Krige/Rausch 2012.

2 Zarakol 2014, 311-332.

3 Adler-Nissen 2014, 143-176.

Gesnerus 43 (2017) 
the outliers, they also reflect, we would argue, the "reach" of the international system itself.

\section{Exploring the other side of the Coin}

Our intent is not to provide an extensive landscape of outliers, but rather to develop questions about the phenomenon. In that sense the article is exploratory. But we wanted to apply these questions to concrete cases. We chose two very different cases, first, Soviet Russia, arguably the paradigmatic political outlier; second, Greece, a "civilizational" outlier stubbornly resistant to foreign assistance. That both cases are European is not coincidental. The aim of the larger work we plan is to examine what the identification of "transgressive" outliers implies about how internationally-minded health statesmen constructed Europe and how they defined the limits of acceptable behavior by European countries.

\section{Political Outlier: Soviet Russia}

For the first two decades after 1917, spokesmen for Soviet public health struggled to overcome their status as international pariah. For all their efforts, Soviet public health was accepted intermittently and unevenly in the international arena. Some players embraced its accomplishments; others excluded its representatives from meetings, exchanges, and programs offering infrastructural and fellowship support.

Soviet health statesmen felt the exclusion keenly. To offset its effects, spokesmen for Soviet public health dispatched representatives to the capitals of Europe to identify opportunities for Soviet participation in international health fora. But the Soviets were not merely supplicants. In the 1920s and early 1930s, spokesmen for Soviet public health pursued their own international agenda. Without emphasizing Bolshevism, they touted the new Soviet medicine, with its free, high quality, and universally accessible health care and its integration of prevention and cure and urged its applicability beyond Russian borders. With some success. Some of the most progressive health statesmen of the inter-war years (John Kingsbury, Ludwik Rajchman, Arthur Newsholme, Andrija Stampar and Henry Sigerist, to name just a few) looked at parts, if not the whole, of the Soviet model as a template for the future. ${ }^{4}$ Simultaneously Soviet public health statesmen tried to ally themselves with other "outliers" like Germany.

4 Birn/Brown 2014.

5 Solomon 2006. 
The inter-war arena that the Soviets sought to penetrate had interesting asymmetries. The League of Nations Health Organization (LNHO), founded in 1921 was "coming to terms with world health" gradually. ${ }^{6}$ Despite its high-flown global mission, LNHO leaders often seemed to be crafting the agenda as they implemented it. The big player in interwar health was the Rockefeller Foundation (RF). By the early 1920s, its pedigree was nearly a decade old, its agenda was clear, its track record in launching international programs was estimable, and its resources seemingly unlimited. ${ }^{7}$ Whatever the asymmetries, in the inter-war years, no single actor could claim exclusive jurisdiction over program ideas, the financial means and infrastructure necessary to implement them, and the renommée needed to effect widespread buy-in. To mobilize these resources required a variety of actors to work together.

Treatments of inter-war health often stress the cooperation of the RF and LNHO. ${ }^{8}$ Understandably so. In 1922, for example, the newly-founded LNHO launched two initiatives: the interchanges of sanitary personnel and the epidemiological intelligence and statistical services. ${ }^{9}$ Ludwik Rajchman, the LNHO Medical Director, apparently had these initiatives in mind as early as 1921, but it was the RF's financial underwriting of these programs that brought them into being.

The sanitary interchanges, with their lectures, site visits and common travel, were designed to create a network of like-minded health administrators based in a variety of countries who would serve as the backbone of fundamental agreements on health administration. The epidemiological intelligence and statistical services were designed to use data from as many countries as possible to generate cross-national comparison of health and disease.

Russia was included in both initiatives. LNHO archival documents reveal that Russia was particularly eager to be included in the sanitary interchanges. The LNHO helped secure passports for the Russians to participate in the 1923 and 1924 interchanges and in the post session travel. ${ }^{10}$ For its part, LNHO was especially eager to have Russia feed data to the epidemiological

6 Borowy 2009.

7 Farley 2004; Weindling 2008.

8 Weindling 1997.

9 These initiatives were listed in the original description of the HO dated January 1922. They were adopted by the Council in September of that year. Geneva League of Nations Archive (hereafter LONA), 12B 18772 /x. Our discussion here draws on Borowy 2009, 100-105.

10 LONA, 12B /26277x/ 25292 le 3 mai, 1925 exchange of letters re Alexander Syssine, Leonard Guinston; Israel Guelman who wanted to participate in the Second Interchange. The folder is entitled "Second exchange of sanitary personnel. Representation of Russia." Ibid., 3 . 
intelligence and statistical services. In late 1921, when it was clear that the Russians were not going to provide data on a reliable basis, LMHO Medical director Ludwik Rajchman hired Lucy Adamowicz, a Warsaw-based member of the Epidemiological Intelligence Bureau to file reports on health conditions in Russia using data from published Russian sources. But Rajchman was eager for unpublished Russian data. ${ }^{11}$ And so, in 1929, he hired A. N. Roubakine, former representative of the Russian Commissariat of Public Health in Paris, to edit the LNHO's Rapports Épidemiologiques, with explicit instructions to include Russian material in cross-national surveys and to write articles on Russian health. ${ }^{12}$ In this way, Rajchman developed a strategy to offset what amounted to the self-exclusion of Russia. ${ }^{13}$

The fact that RF and LNHO cooperated in programs that included Russia should not lead us to assume that these players had similar attitudes toward that country. Indeed, in the early 1920 s, when the RF was underwriting the two LNHO programs of which we spoke, RF agencies with programs relevant to Russia were agonizing over whether to engage with Russia. The RF's International Health Board, founded in 1916 as the "watchtower of public health throughout the world" never extended to Russia either its program to construct public health schools in Europe or its fellowship program to train European health officials in US institutions. The RF's Division of Medical Education, established in 1919, extended to Russia only one of its three emergency programs- the program for medical literature.

One could ascribe this reluctance of RF agencies to the fear of the "Bolshevik bolus," as it was graphically termed in a medical journal. ${ }^{14}$ There was certainly widespread fear of Bolshevism in the RF in the 1920s. But to subsume the disinclination to engage with Russia under the omnibus category of "politics" deprives us of the possibility to determine whether political considerations trumped or reinforced Foundation policy and practice.

The approach of the RF's IHB to capacity building and information gathering differed from the LNHO's. Consider: the International Health Board, committed to making the peaks higher, placed its wager on "brains." The aim was to connect illustrious foreign researchers to mentors, to research situations where they could develop their capacities. Scientific brilliance, not country of origin, was the primary criterion for inclusion in many IHB programs.

11 For Adamowicz, cf. LONA 8A/series 314, Box R5822/23. For examples of her reports on Russia, see LONA R826, 12B 15255, 923 (1924 1 dossier).

12 Paris, A.N. Roubakine, family papers. Geneva correspondence.

13 Solomon/Krementsov 2001.

14 Cunningham, William P., “A Bolshevik Bolus," New York Medical Journal 108 (1918), 1061-1065 as cited in Numbers 1978, 88. 
The medical literature program, launched by the RF's Division of Medical Education (DME) in 1920 as an emergency measure to provide journal subscriptions to impoverished countries, suggests the Foundation's disinterest in creating a network. At its height the medical literature program embraced 17 countries, including Russia and Germany. Internal documents show that the DME acted as a hub, dealing individually with recipients (the spokes). More to the point, the Division studiously ignored information that Russia was receiving books not only from the DME itself, but also from Germany. ${ }^{15}$

The Rockefeller Foundation also had a distinctive approach to factfinding. ${ }^{16}$ RF documents (whether officer's diaries, Foundation Board minutes, inter-office correspondence, memoranda) reflect a near fetish with getting reliable information on countries to which they proposed to extend their programs. Making Russia "readable" in James Scott's terms proved complex, not least because the Foundation resisted hearing the voices of Soviet officials. In early 1922/3, for example, the RF ignored the findings of a questionnaire administered to Soviet health officials by Henry Eversole, Director of the National Information Bureau's Medical Commission, who had spent considerable time in Russia and had met Semashko, the Russian commissar of Public Health. Only in 1928, when Alan Gregg went to Russia for the DME, did the Foundation "hear" official Soviet voices. Even then, the RF agonized over the whether to trust those voices. ${ }^{17}$

What role did politics play in the treatment of outliers? Iris Borowy has suggested that both LNHO and RF combined medicine with politics and considered them two sides of the same coin. ${ }^{18}$ There is, we think, room for discussion here. LNHO did consider wide-ranging assistance a strategy designed to promote the ultimate political goal - namely interstate cooperation. The case of the RF was different. Running like a red thread throughout the RF documents is a horror of getting entangled in politics. That said, as Paul Weindling has underscored, the Foundation's commitment to liberal democracy was a political touchstone. For the RF, capacity building and the improvement of health administration and education were tightly linked to "political stabilization" (which meant avoiding the twin ills of communism and nationalism) ${ }^{19}$

Yet, in 1928, the Foundation did offer some fellowships to Russia. The fancy footwork that enabled this bears rehearsing because it touches directly

15 Solomon 2002, in Gemelli/MacLeod.

16 Solomon 2002, Journal of Policy History.

17 Solomon 2003.

18 Borowy 2009, 99.

19 Weindling 1993. 
on the treatment of "outliers." In 1928, when RF officer Gregg went to Russia to scope out the situation for the Foundation, he had been well briefed on the Soviet political system and its impact on the administration of health. In Moscow, face to face with representatives of the health system and with evidence of how Russian health had been improved, Gregg's vehemence against Bolshevism diminished. Close reading of Gregg's travel diary and final trip report suggests that he squared the circle not by denying the power of Communism in the Soviet Union, nor by declaring Soviet Russia an exception to the RF's championing of liberal political systems, but by relegating Soviet politics to the rubric of "background", i.e., by severing the tight connection between the Soviet political system and public health in Russia. This cleared the way for him to recommend RF fellowship assistance for Russia. In setting aside what colleagues in political science would call "regime type," politics fell out as a criterion for inclusion in RF programs. That criterion would, of course, reappear.

\section{A "civilisational" outlier: Greece}

International shaming does not always produce its intended effect. The best example is that of interwar Greece, ${ }^{20}$ - a sort of decrepit, motionless India of which the LNHO Medical Director wrote to the British Ambassador in Athens in early 1929, saying that: "he (Ludwik Rajchman) had visited most of the countries of the world but never, even in the highlands of Brazil and among peoples whose cultural level was depressed almost to the human minimum, had he found so complete an absence of health and welfare services as existed in Greece". ${ }^{21}$

The LNHO denied that its assessment of Greece was comparative. The League's 1929 Report drafted on the basis of 148 notes and special inquiries drawn from its fact-finding Mission addressed the issue squarely: "We do not attempt to compare Greece with other countries of Europe. Such comparison might be misleading". ${ }^{22}$ Unusual, alien, Greece stood out as an intermediate, disconcerting Erewhon "in Europe but not of Europe". 23 Yet, from the material gathered by the cream of transnational experts (Haven Emerson, Neville Mackenzie, Julius Tandler, etc.) there emerged a sense of a world on the fringes of history. No sewers in a capital of 800000 souls,

20 Theodorou/Karakatsani 2008; Giannuli 1998.

21 Quoted in Sir Percy Loraine to Sir Austen Chamberlain, Confidential, February 4, 1929, PRO FO 286/1067, H1-I1.

22 League of Nations, Health Organisation, "Collaboration with the Greek Government in the Sanitary Re-Organisation of Greece”, Geneva, April 1929, C.162.M.63. 1929.III.

23 Mazower 2000, 9. 
"foecal matter deposited anywhere", "water still sold from the watercart by the bucket" 24 ... it all called to mind a sort of sanitarian old regime in which the Piraeus slaughterhouse - with its carcasses, manure and guts presented hodge-podge, would be the emblem and the flagship.

To be sure, the 'sick heart' of Europe was not short of health ministries working, as in Prague, "at random and in the dark", or as in Romania with "such uncontrolled activity that it bordered on chaos". ${ }^{25}$ But most of those countries, with the encouragement of international agencies, adopted policies that suggested that backwardness could be overcome. The enigma Greece presented to foreign visitors lay not so much in the deficiencies of its health care system - neighbouring Bulgaria displayed more or less similar deficits - but in its disinterest in delivering the desired results, a pervasive lack of 'purposive' intent. Put differently, Greece's oddity lay not in her supposed 'primitivism', but in her disinterest in moving beyond her primitiveness. True, Geneva was stirred by the "dreadful details" that disclosed (in flagrant disregard of international conventions) the widespread employment of children aged 5 to 7 years in carpet, card box making, and shoe repairing industries where conditions of lightning, ventilation, heating, and overcrowding furnished "an almost ideal opportunity for the occurrence of tuberculosis in epidemiological proportions" - the sanatoria happily built "in remote and inaccessible places" proving to be only "homes for the dying". ${ }^{26}$ No wonder health-care institutions were "used to the minimum," so much did they frighten people. ${ }^{27}$

How to explain this perception of Greece as a civilizational outlier? At the time, sanitary culture was widely seen as one of the most important markers of civilization. In the language of the League's 'men-the-spot', we find "essentialist" and undoubtedly prejudiced references to the "Greek mind", "the Greeks as a nation" insulated, closed-off, and, to put it bluntly, "disinclined' to address the shortcomings of its sanitary culture. The helping hand of global agencies' was extended to countries "both anxious and capable of helping themselves". ${ }^{28}$ Passive as it was, rural China was rising up

24 Mackenzie, Melville D., "League of Nations. Health Organisation. Greece. Explanatory Memorandum on the Documentation Collected by the Commission", Confidential, March 9, 1929, CH/Grèce/4, LONA, R5898.

25 Gunn, Selskar M., "Report on a Visit ..." (1920), cité in Page 2001, 271; Crowell, Elisabeth F., Diary, November 11, 1938, Rockefeller Archive Center (hereafter RAC).

26 Tixier, Adrien, "Commission mixte d'hygiène et d'assurance-maladie, Réunion du Secrétariat : 22 février 1929", ILO, SI 2/26/2; Mackenzie 1929, 47-49, 51.

27 Tandler, Julius, "SDN. Organisation d'hygiène. L'hygiène en Grèce”, May 1931, CH 1012, LONA, R5899.

28 Gunn, Selskar M. [1924], quoted in Litsios, Socrates, "The Public Health Life and Times of Selskar Gunn" (on line); on this issue, see Mandler 2013, 259. 
against poor administration in Tinghsien; South Africa could pride herself on the Sidney and Emily Kark's pioneer experiments in social medicine; even India showed islands of rural reconstruction..$^{29}$ Indeed, 'speeding up' time was the 1930s mantra, as in the Romanian countryside where, spurred on by Royal Student Teams, doctors saw tens of patients a day, popes married fifteen couples in one ceremony. ${ }^{30}$ But in Greece, according to the League's fact-finding mission: "there was never any organised service which, except in the interest of politeness, might be called a public health service". ${ }^{31}$ Whether the negative perception of Greece reflected accurately the perceptions of international agencies or whether that portrait was exaggerated for effect remains to be explored.

Whatever the case, the essentialist perception of Greece was laden with implicit comparisons. The most powerful comparator was the Yugoslavia of Andrija Stampar, whose "only politics", we are told, was "people and their needs". ${ }^{32}$ The acid test (invoked by global agencies) of a society bemoaning its health shortcomings made Stampar's Yugoslavia an insider, in contrast to Greece. Whereas Stampar had steadfastly sought to arouse a 'malaria consciousness', the Greek Prime Minister Venizelos incurred the wrath of political opponents merely by taking on some expenses (1930) for the fight against malaria. ${ }^{33}$ Although Yugoslavia had been marked by "complete hygienic illiteracy" after World War I, Stampar pushed the idea of preventive medicine "to its limits" (home economics, eugenics). Greece on the other hand resembled Ottoman Turkey (the dominant "Other"), a country characterized by "a holding of office rather than a rigid performance of duty." 34

Would Athens break out of her nostalgia and pessimism, set her house in order, and become "unrecognizable" in its outlook? ${ }^{35}$ Beneath the discussion of the relative civilisational qualities of European peoples lay the fundamental question of the plasticity of culture. It turned out that culture was not as malleable as the RF 'medicine men' dreamed, that it was not possible to go back to a tabula rasa. In the view of the RF, European reconstruction meant "de-Austrianization," but ossified East European bureaucracies resisted

29 Murard 2008.

30 Musat 2013, 363.

31 C.L. Park, "Memorandum...sur les hôpitaux et l'hygiène publique à Athènes et au Pirée", March 1929, Ch/Grèce/5, LONA, R5898.

32 Van Zile Hyde, Henry, “Oral History Interviews [1975]”, Harry S. Truman Library, quoted in Dugac 2008, 77.

33 Tsiamis/Piperaki/Tsakris 2013, 69; see, too, Balfour 1935, Livadas/Shangos 1941, Barber 1946.

34 Hoover 1915, 30.

35 Venizelos' words [1928], quoted in Mazower 1991, 299. 
injecting "new blood", ousting "the old timers", and more generally embracing a Protestant sense of striving and conscience.

Bringing the family of nations into the tent was an overambitious remit even for the LNHO. Geneva stopped short of a full-blown internationalism, held back by what we would identify as a cultural bar. In 1938 Ludwik Rajchman faced the issue squarely when, urging the LNHO to improve rural life, he narrowed the range of the relevant countries to those of "a certain level of health civilisation". ${ }^{36}$

\section{The next frontier}

This first foray in the writing of a history of public health from the vantage point of outsiders suggests three large questions to be addressed in the larger project.

1. The significance of "outliers" for the understanding of the international system of public health. As Martin Wight pointed out in 1946, the growth of an international system does not imply the growth of internationalism. ${ }^{37}$ An institution's remit may be global, its structure international or intergovernmental, but these features in themselves are no guarantee of internationalism. Was international public health in the inter-war years really "internationalist" in spirit? To us, internationalism implies stressing commonalities rather than differences, acknowledging the diversity of cultures, and assuming that each is valid in its own right. The challenge, of course, is how to accommodate both tolerance and common goals.

2. The relation between outlier status and the "legibility" of societies. The cases presented here suggest that the designation of a society as an "outlier" is more likely when there is no deep knowledge of that society. Recall that international players lacked accurate information on both Soviet Russia and Greece. In Russia, as the 1920s progressed, statistical information became ever more secret, though it was collected with increasing vigor for internal purposes. In Greece, vital statistics were inaccurate and central authorities had no reliable knowledge of local conditions. The relation between "knowing" a country and including it in the family of nations is something to ponder.

3. The markers of outlier status. The cases we examined suggest that some markers of "outlier" status are more easily dealt with than others. When the RF wanted to include Russia in its programs, Alan Gregg relegated Russian political factors to the basket of "context" and concentrated

36 League of Nations Health Committee's $28^{\text {th }}$ Session, Geneva, June 30-July 2, 1938, 40-41. 37 Wight 1978, 78. 
on the technical aspects of health. In the Greek case, it did not prove possible to bracket the marker of sanitary culture/civilization. Is culture, we wonder, inherently harder to crunch than politics? Or does the stickiness of the label "outlier" depend on whether the society being "marginalized" accepts the designation or not? In their eagerness to export the new Soviet model beyond the borders of Russia, Soviet health spokesmen did not foreground their political system. In the case of Greece, statesmen did not seem to want to be in the swim; they lacked the will to modernize. A case of self-exclusion, perhaps? Whether that self-exclusion was a defense mechanism on the part of Greek doctors and bureaucrats or whether it reflected genuine indifference to being part of the international health effort remains to be explored. ${ }^{38}$ And how, we may and we will ask, did the strategy of self-exclusion evident in the Greek case compare to that we noted in the case of Soviet health policy? Close analysis of the Soviet and Greek cases suggests that the rubric of "self-exclusion" can accommodate a variety of motives, a variety of tactics, and a variety of "exit strategies." One of the gains of looking at outliers is to focus our attention on the variety and flux in the international health arena. Some countries remained fixed in the outlier category, others moved in and out. It would be interesting to think about the reluctance of international actors to leave some countries in the category of outliers. The discomfort in the LNHO and RF with consigning to "outlier" status a country that had been and was still a leader in public health (Germany) is well-known. Was that discomfort fueled by a long-standing fabric of transnational relations or by the sense that an international enterprise without Germany was hardly worth the name?

\section{Bibliography}

Adler-Nissen, Rebecca, "Stigma Management in International Relations: Transgressive Identities, Norms, and Order in International Society", International Organization 68 (Winter 2014) 143-176

Balfour, Marshall C., "Malaria Studies in Greece: Measurements of Malaria, 193033", American Journal of Tropical Medicine 15 (1935) 301-330

Barber, Marshall A., A Malariologist in Many Lands (Lawrence 1946)

Birn, Anne-Emanuelle/Theodore Brown (eds.), Comrades in Health: U.S. Health Internationalists, Abroad and at Home (Rutgers 2014)

Borowy, Iris, Coming to Terms with World Health: The League of Nations Health Organisation 1921-1946 (Frankfurt a. M. 2009)

Dugac, Zeljko, "Andrija Stampar (1888-1958): Resolute Fighter for Health and Social Justice", in: Borowy, Iris/Anne Hardy, Of Medicine and Men (Frankfurt a. M. 2008) 73-100

38 Kousis 1933; Makridès 1933; Vassiliou 2005; Zelidis 2008. 
Farley, John, To Cast Out Disease. A History of the International Health Division of the Rockefeller Foundation (1913-1951) (New York 2004)

Giannuli, Dimitra, "'Repeated Disappointment': The Rockefeller Foundation and the Reform of the Greek Public Health System, 1929-40", Bulletin of the History of Medicine 72/1 (1998) 47-72

Hoover, Alden R., The Status of Preventive Medicine in Turkey, with Particular Reference to the Control of Epidemics (State University of Iowa 1915)

Kousis, A. P., "L'Evolution de la médecine en Grèce", Les Balkans III/4-5 (janvierfévrier 1933) 323-375

Krige, John/Helke Rausch (eds.), American Foundations and the Coproduction of World Order in the Twentieth Century (Göttingen 2012)

Livadas, G.A./J.C. Sphangos, Malaria in Greece (1930-1940) (Athens 1941)

Makridès, N., Hai hyperesiai hygieines en Helladi [Health Services in Greece] (Athens 1933)

Mandler, Peter, Return from the Natives. How Margaret Mead Won the Second World War and Lost the Cold War (New Haven 2013)

Mazower, Mark, Greece and the Interwar Economic Crisis (Oxford 1991)

Mazower, Mark, The Balkans (London 2000)

Murard, Lion, "Designs within Disorder: International Conferences on Rural Health Care and the Art of the Local, 1931-1939", in Solomon, S. Gross/Lion Murard/ Patrick Zylberman (eds.), Shifting Boundaries of Public Health: Europe in the Twentieth-Century (Rochester, NY 2008) 111-134

Musat, Raluca, "'To Cure, Uplift and Ennoble the Village': Militant Sociology in the Romanian Countryside", East European Politics and Societies and Cultures 27/3 (August 2013) 353-375

Numbers, Ronald, Almost Persuaded: American Physicians and Compulsory Health Insurance, 1912-1920 (Baltimore 1978)

Page, Benjamin, "First Steps: The Rockefeller Foundation in Early Czechoslovakia", East European Quarterly 35/3 (September 2001) 259-308

Solomon, Susan Gross/Nikolai Krementsov, "Giving and Taking Across Borders: The Rockefeller Foundation and Russia, 1919-1928”, Minerva 39 (2001) 265-298

Solomon, Susan Gross, "The Power of Dichotomies: The Rockefeller Foundation, the Medical Literature Program and Russia, 1921-1925," in Gemelli, Giuliana/ Roy MacLeod (eds.), American Foundations in Europe, 1920-1990 (New York 2002) 31-51

Solomon, Susan Gross, "Fact Finding and Policy Making: The Rockefeller Foundation's Division of Medical Education and the 'Russian Matter,' 1925-1927,', Journal of Policy History 14/4 (2002) 384-417

Solomon, Susan Gross, "Local Knowledge or Knowledge of the Local: Rockefeller Foundation Officers Site Visits to Russia in the 1920s," Slavic Review (Winter 2003) 710-733

Solomon, Susan Gross (ed.), Doing Medicine Together: Germany and Russia Between the Wars (Toronto 2006)

Theodorou, Vassiliki/Despina Karakatsani, "Health Policy in Interwar Greece: The Intervention of the League of Nations Health Organisation", Dynamis 28 (2008) $53-75$ 
Tsiamis, Costas/E.-T. Piperaki/A. Tsakris, "The History of the Greek Anti-Malaria League and the Influence of the Italian School of Malariology", Le Infezioni in Medicina 1 (2013) 60-75

Vassiliou, Maria, "Politics, Public Health, and Development: Malaria in $20^{\text {th }}$ Century Greece", D.Phil., Modern History (Oxford 2005)

Weindling, Paul, "Public Health and Political Stabilisation: The Rockefeller Foundation in Central and Eastern Europe between the two wars," Minerva 31/3 (1993) 253-267

Weindling, Paul (ed.), International Health Organisations and Movements 19181939 (Cambridge 1995)

Weindling, Paul, "Philanthropy and World Health: The Rockefeller Foundation and the League of Nations Health Organization," Minerva 35/3 (1997) 269-281

Weindling, Paul, "American Foundations and the Internationalizing of Public Health," in Solomon/Murard/Zylberman (eds.), Shifting Boundaries of Public Health (Rochester, NY 2008) 63-86

Wight, Martin, Power Politics (London 1978 [1946])

Zarakol, Ayse, "What made the modern world hang together: socialisation or stigmatisation? International Theory 6 (2014) 311-332

Zelidis, C., "The Epidemiological Situation in Greece during the Interwar Period and the Policy for Health Services Reorganization" (in Greek), in Kyriopoulos G./ Karela, A. (eds.), Dimosia ygeia kai koinoniki politiki: O Eleftherios Venizelos kai i epochi tou (Athens 2008) 